\title{
Application Measurement Tools of Luxmeter and White Diode Laser as Alternative Methods in Distinguishing Oil Candles Based Mixed the Light Intensity
}

\author{
Anis Bahirah", Aji Rahmadi**, Frida Agung Rakhmadi ${ }^{* *}$ \\ Physics Department, Faculty of Science and Technology, UIN Sunan Kalijaga \\ J1. Marsda Adisucipto No.1 Yogyakarta 55281, Indonesia, Telp. +62-274-540971, Fax. +62-274-519739 \\ E-mail: bahirahku@gmail.com*, ajirahmadi64@gmail.com ${ }^{* *}$,frida.rakhmadi@uin-suka.ac.id***
}

\begin{abstract}
Research about the application of Luxmeter measuring instrumental with white diode laser to distribute the light intensity in pure or candle-contaminated cooking oil. This research is conducted by varying the range, so the result of intensity value is acquired. The result of research shows that there are differences in the light intensity value of both pure and candle-contaminated cooking oil. The output of measuring instrument in this research shows a different number between pure cooking oil and candle-contaminated cooking oil. Based on the data analyzed, $5 \mathrm{~cm}$ range from the Luxmeter sensor is the most sensitive area. From the calculation, the value acquired is $273,1349 \pm 0.06 \mathrm{Cd}$, that means if the reading value is more than that value, the oil is identified as candle-contaminated if less the oil is pure.
\end{abstract}

Keywords: Cooking oil, Luxmeter, White laser diodes

\section{INTRODUCTION}

Food oil that we commonly known as cooking oil is a basic human need as a food processing tool (Adi, 2018). Frying is a process that is commonly done by the community every day. In the frying process, cooking oil functions as a heat transfer medium, adding savory flavors and calories in food ingredients (Rany, 2018). Lately, there is oil mixed with wax on the market (Emy, 2017). This is clearly very dangerous for human health, therefore we must be able to choose and distinguish the oil.

The parameters that must be considered in choosing oil quality. Oil quality parameters include physical and chemical properties. The physical properties of oil include density, color, odor, solubility, melting point, boiling point, softening point, slipping point, shot melting point, specific gravity, viscosity, refractive index, turbidity point, smoke point, flash point and hotspot (Sutiah et al., 2008).

From several parameters, there are physical types that can be distinguished to determine oil quality. Pure oil and oil mixed with wax have different types of time, so if we can distinguish so we can know the purity of the oil. Of the different types of species, if given light will differ the intensity of light passing through it.

Therefore, testing was conducted to determine the intensity of light in pure oil and mixed with wax to further find the value as a limiting difference in the oil. Once this value is obtained, a detection system can be made to distinguish pure oil and wax mixture.

\section{MATERIALS AND METHODS}

\section{Tools and Materials}

The ingredients that need to be prepared are two different oil samples. One sample of pure oil and one oil sample mixed with $50 \mathrm{ml}$ of wax. The tool used in data retrieval is Lux Meter with the help of white laser diodes.

\section{Data Collection Method}

The process of taking data using a method of measuring light intensity using Lux Meter. This measurement method can be used to measure the intensity of light penetrating oil liquid. The principle of this tool is a certain distance will show the difference in the value of the light intensity that is the highest difference.

Data retrieval is done by varying the measurement 10 times with a $5 \mathrm{~cm}$ to $50 \mathrm{~cm}$ range with each $5 \mathrm{~cm}$ taken and data retrieval is in the light-resistant Labolatorium room.

The data that has been obtained is then analyzed how the characteristics can then be used to determine whether the data can be continued in the manufacture of detection devices or not. The highest difference data will be used as a reference point for a detection system. The detection system that will be made is to use the LDR sensor with the sample placement according to the highest difference with the help of a white laser diode. 


\section{Data Processing}

The data processing method above is by determining the difference between lux meter readings of each distance variation.

How to find the biggest difference is by subtracting the results of lux meter reading every $5 \mathrm{~cm}$ to the previous result. Once the biggest difference is known, the lux meter reading data can be retrieved to find the average value. The average yield data is used as a unit of light intensity, namely Candela with;

$$
\mathrm{I}=((\ldots \mathrm{Lux}) * 0,09290304) \mathrm{Cd}
$$

By obtaining the highest difference point, the point can be used as the most appropriate point between the position of the laser, material, and sensor. Average data can be included in the program to be used as a limiting point to distinguish material.

\section{RESULTS AND DISCUSSION}

\section{Data Processing}

The results of data processing with equation 1 are shown in table 1 .

Table 1. Data collection of Lux meter.

\begin{tabular}{lll}
\hline Distance (cm) & Pure Oil (Lux) & $\begin{array}{l}\text { Mixing Oil Wax } \\
\text { (Lux) }\end{array}$ \\
\hline 5 & 3850 & 2030 \\
10 & 1344 & 827 \\
15 & 635 & 416 \\
20 & 366 & 249 \\
25 & 227 & 153 \\
30 & 161 & 104 \\
35 & 123 & 78 \\
40 & 94 & 60 \\
45 & 76 & 45 \\
50 & 62 & 37 \\
\hline
\end{tabular}

Then from the results of data analysis, the biggest change is that at a distance of $5 \mathrm{~cm}$ from the large Lux meter the change is $232.815 \mathrm{Cd}$ for pure oil and
111.7624 Cd for waxed oil. So that the data is taken at a distance of $5 \mathrm{~cm}$, and the amount of data at that distance is $357.6767 \mathrm{Cd}$ for pure oil and 188.593 Cd for oil mixed with wax.

Thus the result of processing Lux meter reading data at a distance of $5 \mathrm{~cm}$ is $273.134 \mathrm{Cd}$ which means that at that distance can be used as the best point to make the detection system and the value can also be used as reference points to be used as the midpoint of the program to be made.

\section{CONCLUSIONS}

The result concluded that there are differences in the light intensity value of both pure and candlecontaminated cooking oil. The output of measuring instrument in this research shows a different number between pure cooking oil and candle-contaminated cooking oil. Based on the data analyzed, $5 \mathrm{~cm}$ range from the Lux meter sensor is the most sensitive area. From the calculation, the value acquired is $273,1349 \pm$ $0.06 \mathrm{Cd}$, that means if the reading value is more than that value, the oil is identified as candle-contaminated if less the oil is pure.

\section{REFERENCES}

Mangidi, Alfahru. 2015. Practice report Physical Chemistry II Experiment II Determination of Surface Tension Creep Capillary Fluid Method. Haluoleo university Kendari

Maryani, H., Rukmini. And Ward, YF. (2007) "Participation of communities, Cross Private Sector In Posyandu revitalization". Health Systems Research Bulletin, Vol. 10, No. April 2nd; $145-$ 150

Thandeus MS. 2005. Effect of Vitamin C and Vitamin E Against Liver histological changes, heart and aorta Musmusculus L Gulur Switzerland derrived Aubat Provision Used Cooking Oil. [Thesis]. University of Indonesia.

Tuasamu,

Rany.2018.https://www.researchgate.net/publication/32581_Ba haya_Penggunaan_Minyak_PengGorengan_Berulan_Diliat_Dar i_Angka_Peroksidanya (Accessed on 8 October 2018). 